Stem cells

\section{Stem cells and neurological disease}

\section{R A Barker, M Jain, R J E Armstrong, M A Caldwell}

\section{The therapeutic implications and application of stem cells for} the nervous system

$\mathrm{T}$ here has recently been a great deal of interest in stem cells and the nervous system, in terms of their potential for deciphering developmental issues as well as their therapeutic potential. In this editorial we will critically appraise the different types of stem cells, their therapeutic implications, and the applications to which they have been put, with the hope that the hype that surround these cells can be distinguished from the scientific reality.

\section{WHAT ARE STEM CELLS?}

Stem cells were originally defined in the haematological system, but more recently have been found in a multitude of other sites, including the brain. These cells all share the same properties of self-renewal and multipotentiality ${ }^{1}$ and various different types and therapeutic strategies have been defined with respect to the nervous system (Table l, fig l).

The reasons for these cells receiving such attention for the treatment of neurological disorders relates to their:

(a) capacity to proliferate in culture with the prospect that large numbers of cells can be derived from a limited source;

(b) potential to be harvested from the patients themselves; (c) ability to migrate and disseminate following implantation within the adult CNS;

(d) possible tropism for areas of pathology;

(e) ease of manipulation using viral and non-viral gene transfer methods;

(f) ability to better integrate into normal brain cytoarchitecture with the potential for physiologically regulated release of substances.

We will briefly discuss the different types of stem cells and how they have been applied to neurological disease, especially Parkinson's disease, given the accepted view that this is the disease most amenable to cell replacement therapy.

\section{EMBRYONIC STEM CELLS}

Embryonic stem cells are derived from the inner cell mass of the embryonic blastula and are pluripotent with great proliferative potential, although with this comes the risk of teratomas. Much of the work to date has concentrated on mouse derived embryonic stem cells, which can be made to differentiate into neurons, including dopaminergic neurons. ${ }^{2}$ These latter cells have been shown to survive and ameliorate behavioural deficits in an animal mode of Parkinson's disease, ${ }^{3}$ although in this study $20 \%$ of rats still developed teratomas at the transplant site. In contrast, Kim et al, using a different approach that relies on transfection with Nurrl (a transcription factor involved in the differentiation of dopaminergic cells), have demonstrated functional efficacy without tumour formation. ${ }^{4}$

Human embryonic stem cells have now been isolated ${ }^{5}$ and grown in culture with enrichment for neuronal lineages, possible through exposure to a combination of growth factors and mitogens. ${ }^{6}$ These cells, when placed in the developing rat brain, can migrate widely and differentiate in a site specific fashion without the formation of teratomas. ${ }^{7}$ However, the safety of these cells needs further investigation before they can be considered for clinical use. Furthermore, the sensitive nature of this technology and the ethical issues surrounding it make it a very controversial source of tissue for cell replacement therapy and in this respect the issue of therapeutic cloning is a major concern. ${ }^{8}$

\section{ADULT NEURAL PRECURSOR CELLS}

One of the long held dogmas is that neurogenesis in the adult mammalian central nervous system (CNS) does not occur, although there is now ample evidence to suggest that this is not the case. New neurons are derived in adulthood from a population of adult neural precursor cells (NPCs), which are primarily found in the subependymal layer of the ventricular zone and the dentate gyrus of the hippocampus, although they are also probably found in other sites. ${ }^{10}$ However, the behaviour of the NPCs found in all these sites is different, and may relate as much to the environment in which

Table 1 Essential properties of stem cells for use in clinical transplantation

\begin{tabular}{ll}
\hline Disease & Principle function required of stem cells \\
\hline Cell replacement & Nigrostriatal dopamine neurons \\
Parkinson's disease & GABAergic striatal projection neurons \\
Huntington's disease & Diffuse neuronal replacement, including basal forebrain cholinergic \\
Alzheimer's (and other dementias) & Nigrostriatal and striatal output neurones \\
Multiple system atrophy (MSA) & Hippocampal neurones especially those of CA 1 \\
Hippocampal damage (eg global ischaemia) & Broad phenotypes required; dependent on site \\
Focal ischaemic damage & Broad phenotypes required; dependent on site \\
Traumatic brain injury & Projection neurones (glutamate); remyelination \\
Spinal injury & Replacement of alpha motorneurons \\
Amyotrophic-lateral sclerosis & Remyelination through oligodendrocytes \\
Multiple sclerosis and other demyelinating conditions & \\
& \\
Drug delivery & Local GABA \\
Epilepsy & Analgesic compounds such as met-enkephalin and endorphins \\
Chronic pain & Metabolic enzymes \\
Genetic defects, eg & $\beta$-glucuronidase \\
Mucopolysaccaroidosis VII & $\beta$-hexosaminidase A \\
Tay-Sachs disease & Anti-mitotic drug; modified viruses \\
Intracerebral malignancy & Support of diverse neuronal populations \\
"growth factor responsive conditions" &
\end{tabular}


Primordial germ cells in

gondal ridge of embryo

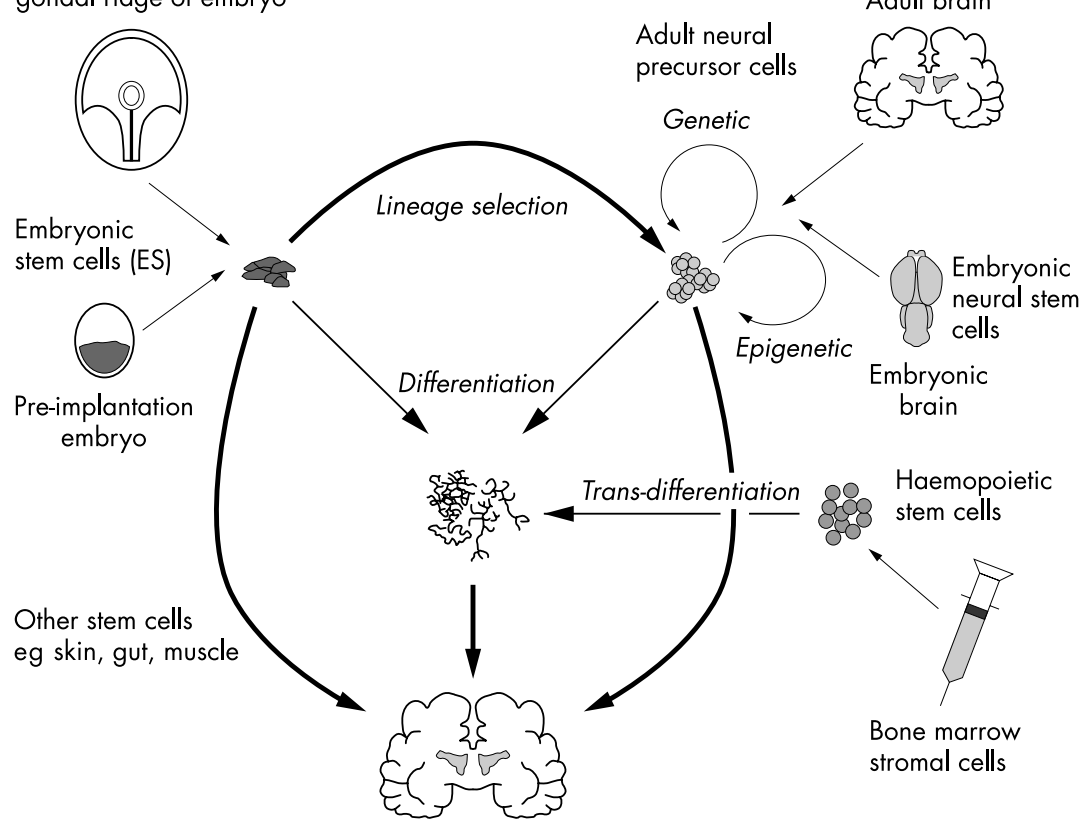

The different types of stem cells

they find themselves as to their intrinsic properties. For example, nigral NPCs appear to only differentiate into astrocytes in situ or when grafted to the adult nigra, but when they are cultured in vitro or transplanted into the hippocampus they can form neurons. ${ }^{11}$ The function of these newborn neurons in the adult CNS is not known but they do have the characteristics of mature neurons with appropriate neurophysiological properties and evidence of integration into neuronal networks with functional synaptic transmission and behavioural effects. ${ }^{12}{ }^{13}$

Although much of this work has been done in rodents there is now evidence of neurogenesis in the adult human hippocampus, ${ }^{14}$ with cells being grown from the adult human CNS. ${ }^{15}$ Thus, the potential for autologous grafts is possible, assuming that the NPCs are not themselves involved in the disease process, ${ }^{16}$ and has indeed already been attempted in one patient with Parkinson's disease. ${ }^{17}$

\section{BONE MARROW AND \\ NON-NEURAL STEM CELLS}

An alternative source of autologous cells for grafting in patients with neurological disease are those derived from nonneural sources including the bone marrow, which contains a range of stem cells. This includes the haematopoietic stem cell, which when transplanted into irradiated recipients can migrate into the brain and differentiate into microglia, astrocytes, and possibly neurons. ${ }^{18}$ In addition, there are mesenchymal stem cells or bone marrow stromal cells, which when engrafted into the adult brain are capable of migration and survival and in vitro can be made to express markers of astrocytes, oligodendroglia, and neurons. ${ }^{19}$

Indeed they have even been associated with some functional benefit in a rodent model of Parkinson's disease when transfected with the dopamine synthetic enzyme tyrosine hydroxylase. ${ }^{20}$ However, the robustness and efficiency of this system to produce neural cells is still poor, as is its widespread applicability to other types of non-neural stem cells. There is some evidence from cDNA microarray analysis that different stem cells may in fact have similar phenotypic potential irrespective of origin ${ }^{21-23}$ and, therefore, it is theoretically possible that stem cells derived from non-neural systems may be used for neural cell therapy through a transdifferentiation process. However, there have been recent concerns that such a process may be a result of cell fusion-namely adult somatic cells can by fusion with less differentiated cells. ${ }^{24} 25$

\section{EMBRYONIC NEURAL STEM CELLS (NSCs)}

Most of the work on stem cells and the CNS refers to NSCs that are derived from the neuroepithelium of the developing embryo. These cells respond in vitro to mitogens such as epidermal growth factor (EGF) and fibroblast growth factor (FGF2), and it is possible to expand cells from any region of the brain. ${ }^{26}{ }^{27}$ As development progresses to adulthood there is considerable debate over the origin of NSCs, with recent suggestions that appear to gain differentiation potential these cells may also originate from glia. ${ }^{28}$ Radial glia have classically been considered to be "scaffolding" cells along which cortical neuroblasts migrate to reach their final destination, after which they differentiate into astrocytes. However, recent in vitro and in situ studies suggest that the radial glial cells may be responsible for the production of newborn neurons, as well as their guidance to their final destinations within the cortex. $^{29}$ The exact relationship of this cell type to the NSCs derived from the neuroepithelium is yet to be elucidated, although it is possible that as developmental time increases, stem cells have either neuroepithelial, radial glial, or finally astroglial characteristics, which all share the characteristic of nestin expression. ${ }^{28}$

The isolation of these cells is complicated because their culturing inevitably leads to a mixed population of progenitor and stem cells, which can better be described as expanded neural precursors (ENPS). In addition, the proliferation of ENPs in culture is not indefinite because there appears to be a set number of population doublings - the so-called "Hayflick limit", equivalent to approximately 50 population doublings ${ }^{30}$ after which non-transformed cells enter replicative senescence and stop dividing. This effect seems to be species dependent, and although greater for human than rodent ENPs, obviously has important implications for their clinical application. Attempts to circumvent this problem with human cells has employed either a modification of the culture technique $^{31}$ or the use of transducing vectors encoding an immortalising oncogene. ${ }^{32}$ These genetic manipulations may alter the behaviour of these cells even without tumorigenesis, and thus extrapolation of results from such cells to those found in the developing and adult CNS must be carried out with caution.

For ENPs to be of clinical value, they not only need to be propagated long term in culture, but must be able to differentiate appropriately, which is influenced both by intrinsic and external factors, such as the culture conditions. ${ }^{33}$ This having been said, neurons differentiating from growth factor responsive ENPs are typically GABAergic in phenotype, irrespective of species or region from which the cells were harvested in the embryo. ${ }^{34}$ So for most disorders, especially Parkinson's disease, it will be necessary to switch or regulate their fate and a number of factors and methods have been suggested for the generation of dopaminergic neurons based on factors known to be important in their normal development (see also embryonic stem cell section; see figure 2 ).

Exposure of ENPs to sonic hedgehog $(\mathrm{Shh})^{36}$ or transcription factors, including nurrl,${ }^{37}$ has been shown to increase 


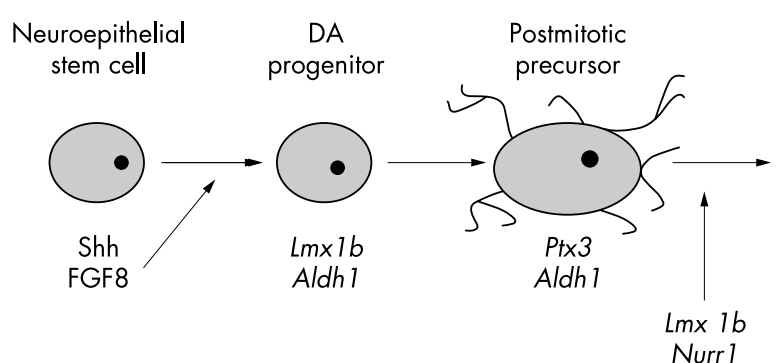

$\operatorname{Lm} \times 1 b$
Nurr 7

Development of midbrain dopamine (DA) neurons. Initial specification requires the patterning information that is provided by sonic hedgehog (shh) and fibroblast growth factor 8 (FGF8). The $[m \times 1 b$ and nurr 1 transcription factors are essential for different aspects of DA differentiation. The ptx 3 transcription factor and the retinoid synthesising enzyme Aldh 1 are specific markers of developing DA neurons in the ventral midbrain, but their roles are still largely unknown. Adapted from Goridis \& Rohrer, 2002.35

the yield of dopaminergic neurons obtained from these cells, although not all cell types respond to such stimulation, for example hNT neurons. ${ }^{38}{ }^{39}$ However, in most cases only small numbers of such neurons emerge from these manipulations, and thus the search continues for a reliable culture method to obtain sufficient numbers of dopaminergic neurons.

\section{TRANSPLANTATION OF NEURAL STEM CELLS FOR THE TREATMENT OF NEUROLOGICAL DISEASE}

The behaviour of embryonic NSCs following transplantation varies depending on the source of cell and animal model. In the case of human ENPs and the intact adult brain, it has been shown that they are able to generate neurons in vivo in regions of active neurogenesis such as the SVZ and hippocampus, ${ }^{40}$ but not when placed in non-neurogenic areas such as the striatum..$^{41}$ The situation may be different in the diseased or damaged CNS (see table 1).

\section{Parkinson's disease}

Early transplant studies using human ENPs showed some survival and dopaminergic differentiation, but the numbers were low. ${ }^{42}$ This may relate to

Essential properties of stem cells for use in clinical transplantation

- Capable of clonal propagation in vitro to ensure homogeneity

- Genetic stability at high passage

- Integration within the host brain following transplantation

- Connectivity within host circuits

- Migration and engraftment at sites of damage

- Correct differentiation into appropriate neural cell types

- Functional benefits

- Lack of side effects the fact that in vitro, NPCs derived from the developing ventral mesencephalon lose the ability to spontaneously differentiate into dopaminergic cells after only a few divisions. ${ }^{43}$

Thus, "pre-differentiation" of the ENPs prior to implantation would seem logical and this approach has been adopted with some success by Studer and colleagues. ${ }^{44}$ An alternative approach has been to employ ex vivo genetic techniques to modify cells prior to implantation to express tyrosine hydroxylase, which again has met with some success. ${ }^{45}$

\section{Huntington's disease}

Transplantation repair in Huntington's disease provides different challenges for ENPs, in that the transplanted cells must homotypically reconstruct circuitry. To date, studies using NSCs in this disorder are limited but there is some evidence of appropriate neuronal differentiation with human NSCs, ${ }^{46}$ although the functional efficacy and connectivity of these cells in repairing the brain has not been demonstrated.

\section{Cerebral ischaemia}

Cell replacement therapy for ischaemic injury has experimentally shown some promise. For example, transplantation of the MHP36 line (ReNeuron holdings) has been reported to ameliorate cognitive deficits in rodent models of ischaemia. ${ }^{47}$ However, the applicability of these findings to ENPs in general is uncertain because other similarly derived multipotential cell lines do not show such an ability. ${ }^{48}$ hNT neurons derived from a human teratocarcinoma cell line have also been shown to alleviate motor and behavioural deficits in animal models of ischaemia, ${ }^{49}$ although it is hard to attribute the functional recovery to circuit reconstruction given the histological findings. ${ }^{50}$ Nevertheless, some investigators have deemed this to be sufficient data to move to a clinical trial in patients with basal ganglia stroke and resultant motor deficits. Reassuringly, there has been no evidence for tumorigenesis or other adverse effects in the 12 patients who have been reported in the phase I study, although preliminary functional and imaging data are difficult to interpret because of the lack of an adequate control group. ${ }^{51}$ There is, however, at least some evidence of cell survival based on postmortem data 27 months post-transplantation. ${ }^{52}$

\section{Demyelinating diseases}

ENPs are also being considered to replace glial cells that have been lost to demyelinating or dysmyelinating disease. Animal models of global hypomyelination (eg the shiverer (Shi) mouse) have been used to examine the ability of transplanted ENPs to myelinate axons. Oligodendrocytes constitute a very small component of the differentiated cells that emerge spontaneously in vitro from both EGF/FGF-2-expanded $\mathrm{ENPs}^{27}$ and most of the genetically immortalised stem cell lines. ${ }^{53}$ However, when such cells are transplanted into the myelin deficient environment, an increase in oligodendroglial differentiation has been reported, which is associated with some myelination and in some cases a degree of functional recovery. ${ }^{53} 54$

\section{APPLICATIONS OF NSCs AS VECTORS FOR THE DELIVERY OF BIOLOGICALLY ACTIVE SUBSTANCES}

In addition to their potential to directly replace cells lost to disease and thereby reconstruct the CNS, NSCs might also serve a role as efficient and flexible vectors for the sustained, local delivery of neuroactive compounds to the brain-eg neurotrophic factors for neuroprotection, or to replace proteins lost because of single gene defects. In most envisioned scenarios this would involve genetically engineering the NSCs to direct, and regulate, the expression of therapeutic gene products (ex vivo gene therapy).

\section{Treatment of genetic disorders}

The aetiology of a number of rare, but devastating, inherited neurological conditions can be fully attributed to the loss of function of a single gene that encodes for a metabolically or developmentally critical enzyme. The ability of stem cells to deliver functional enzymes diffusely in such neurogenetic degenerative conditions has been explored in some prototypical animal models such as that for mucopolysaccharidosis type VII (MPS VII, Morquio). ${ }^{55}$

\section{Neurotrophins and cytokines for neuroprotection}

The understanding that the differentiation and survival of neurons in development is dependent on them receiving 
adequate and specific trophic support has meant that a number of cell delivery systems have been examined, including NSCs. Such a delivery strategy is attractive compared to a viral vector based delivery system because the host brain is not genetically manipulated, preventing insertional mutagenesis and preserving the function of neurons in the host. In addition, NSCs can be fully characterised such that the level of production of the growth factor can be standardised, and, finally, extra safety features could be incorporated, such as a "suicide cas-

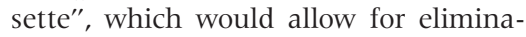
tion of cells should it be necessary. ${ }^{56}$

\section{Chemotherapeutic agents}

Obtaining adequate local concentrations of cytotoxic drugs impedes the chemotherapy of primary brain tumours. Based on their previous work indicating that the C17.2 NSC line was highly migratory in the adult brain, Snyder and colleagues retrovirally transfected this cell line to express the anti-mitotic compound cytosine deaminase. These cells were implanted into animals with experimentally induced gliomas and appeared to migrate preferentially towards the tumours, which decreased in size. ${ }^{57}$ In a similar vein, the same group has recently reported a method by which the migratory ability of this line can be harnessed as a "Trojan horse" to deliver therapeutic viruses to intracerebral tumours. ${ }^{58} 59 \mathrm{Al}$ though such results require confirmation and more characterisation, they suggest that certain ENPs may show a tropism for areas of pathology and may be of use in chemotherapy.

\section{Drug discovery and therapeutics}

Finally, stem cells are an attractive option for commercial organisations interested in drug discovery. ${ }^{39}$

\section{CONCLUSION}

Stem cells are emerging as one of the most exciting new areas of neuroscience, not only in terms of revealing insights into normal development, but also as a therapeutic agent for a range of neurological diseases. In both of these aspects, they will impinge on neurological practice by providing insights into mechanisms of disease as well as curative cell therapies. However, the development of such approaches requires patience and any translation from the laboratory to the clinic must be undertaken slowly and based on sound experimental data. A failure to do so will not only undermine those involved in this type of research, but will prematurely dash the hopes of many patients and their neurologists.

\section{ACKNOWLEDGEMENTS}

The authors' own works are supported by the MRC, PDS, Royal Society and Merck Sharp, and
Dohme. We apologise to all those whose work has not been cited because of space constraints.

J Neurol Neurosurg Psychiatry 2003;74:553557

\section{Authors' affiliations}

\section{R A Barker, M Jain, R J E Armstrong,}

M A Caldwell, Cambridge Centre for Brain Repair, Forvie Site, Robinson Way, Cambridge CB2 2PY, UK

Correspondence to: R A Barker;

rab46@cus.cam.ac.uk

\section{REFERENCES}

1 Gage FH, Ray J, Fisher L. Isolation, characterization, and use of stem cells from the CNS. Annu Rev Neurosci 1995; 18:159-92.

2 Lee SH, Lumelsky N, Studer L, et al. Efficient generation of midbrain and hindbrain neurons from mouse embryonic stem cells. Nat Biotechnol 2000; 18:675-9.

3 Bjorklund LM, Sanchez-Pernaute R, Chung S, et al. Embryonic stem cells develop into functional dopaminergic neurons after transplantation in a Parkinson rat model. Proc Natl Acad Sci USA 2002;99:2344-9.

$4 \mathrm{Kim}$ JH, Auerbach JM, Rodriguez-Gomez JA, et al. Dopamine neurons derived from embryonic stem cells function in an animal model of Parkinson's disease. Nature 2002;418:50-6.

5 Thomson JA, Itskovitz-Eldor J, Shapiro SS, et al. Embryonic stem cell lines derived from human blastocysts. Science 1998;282: 1 145-7.

6 Carpenter MK, Inokuma MS, Denham J, et al. Enrichment of neurons and neural precursors from human embryonic stem cells. Exp Neurol 2001;172:383-97.

7 Zhang SC, Wernig M, Duncan ID, et al. In vitro differentiation of transplantable neural precursors from human embryonic stem cells. Nat Biotechnol 2001;19:1129-33.

8 Wakayama T, Tabar V, Rodriguez I, et al. Differentiation of embryonic stem cell lines generated from adult somatic cells by nuclear transfer. Science 2001;292:740-3.

9 Gage FH. Neurogenesis in the adult brain. J Neurosci 2002;22:612-3.

10 Gould E, Reeves AJ, Graziano MS, et al. Neurogenesis in the neocortex of adult primates. Science 1999;286:548-52.

11 Lie DC, Dziewczapolski G, Willhoite AR, et al. The adult substantia nigra contains progenitor cells with neurogenic potential. J Neurosci 2002;22:6639-49.

12 Song HJ, Stevens CF, Gage FH. Neural stem cells from adult hippocampus develop essential properties of functional CNS neurons. Nat Neurosci 2002;5:438-45.

13 Shors TJ, Miesegaes G, Beylin A, et al. Neurogenesis in the adult is involved in the formation of trace memories. Nature 2001;410:372-6

14 Eriksson PS, Perfilieva E, Biork-Eriksson T, et al. Neurogenesis in the adult human hippocampus. Nat Med 1998;4:1313-7.

15 Palmer TD, Schwartz PH, Taupin P, et al. Cell culture progenitor cells from human brain after death. Nature 2001:41 1:42-3.

16 Armstrong RJ, Barker RA. Neurodegeneration: a failure of neuroregeneration? Lancet 2001; 358: 1174-6

17 Levesque MF, Neuman T. Autologous transplantation of differentiated dopaminergic neurons for Parkinson's disease: long term post-operative, clinical and functional metabolic results. Exp Neurol 2002;175(2): 425.

18 Mezey E, Chandross KJ. Bone marrow: a possible alternative source of cells in the adult nervous system. Eur J Pharmacol 2000;405:297-302

19 Priller J, Persons DA, Klett FF, et al. Neogenesis of cerebellar Purkinje neurons from gene-marked bone marrow cells in vivo. J Cell Biol 2001;155:733-8.
20 Schwarz EJ, Alexander GM, Prockop DJ, et al. Multipotential marrow stromal cells transduced to produce L-DOPA: engraftment in a rat model of Parkinson disease. Hum Gene Ther 1999;10:2539-49.

21 Terskikh AV, Easterday MC, Li L, et al. From hematopoiesis to neuropoiesis: evidence of overlapping genetic programs. Proc Natl Acad Sci USA 2001 ; 98:7934-9.

22 Ramalho-Santos M, Yoon S, Matsuzaki Y, et al. "Stemness": transcriptional profiling of embryonic and adult stem cells. Science 2002;298:597-600

23 Ivanova NB, Dimos JT, Schaniel C, et al. A stem cell molecular signature. Science 2002;298:601-4.

24 Terada N, Hamazaki T, Oka M, et al. Bone marrow cells adopt the phenotype of other cells by spontaneous cell fusion. Nature 2002;416:542-5.

25 Ying QL, Nichols J, Evans EP, et al. Changing potency by spontaneous fusion. Nature 2002;416:545-8

26 Hitoshi S, Tropepe V, Ekker M, et al. Neural stem cell lineages are regionally specified, but not committed, within distinct compartments of the developing brain. Development 2002;129:233-44.

27 Ostenfeld T, Joly E, Tai YT, et al. Regional specification of rodent and human neurospheres. Brain Res Dev Brain Res 2002;134:43-55.

28 Alvarez-Buylla A, Garcia-Verdugo JM, Tramontin AD. A unified hypothesis on the lineage of neural stem cells. Nat Rev Neurosci 2001;2:287-93.

29 Noctor SC, Flint AC, Weissman TA, et al. Dividing precursor cells of the embryonic cortical ventricular zone have morphological and molecular characteristics of radial glia. $J$ Neurosci 2002;22:3161-73.

30 Hayflick L. Mortality and immortality at the cellular level. A review. Biochemistry (Mosc.) 1997:62:1180-90.

31 Svendsen CN, ter Borg MG, Armstrong RJ, et al. A new method for the rapid and long term growth of human neural precursor cells. J Neurosci Methods 1998:85:141-52.

32 Villa A, Rubio FJ, Navarro B, et al. Human neural stem cells in vitro. A focus on their isolation and perpetuation. Biomed Pharmacother 2001;55:91-5.

33 Caldwell MA, He X, Wilkie N, et al. Growth factors regulate the survival and fate of cells derived from human neurospheres. Nat Biotechnol 2001;19:475-9.

34 Jain $M$, Armstrong R, Tyers P, et al. The predominant neurochemical phenotype of neurons derived from expanded human neural precursor cells in vitro is GABA. Exp Neurol 2003; in press.

35 Goridis C, Rohrer H. Specification of catecholaminergic and serotonergic neurons. Nat Rev Neurosci 2002:3:531-541.

36 Matsuura N, Lie DC, Hoshimaru M, et al. Sonic hedgehog facilitates dopamine differentiation in the presence of a mesencephalic glial cell line. J Neurosci 2001;21:4326-35.

37 Wagner J, Akerud P, Castro DS, et al. Induction of a midbrain dopaminergic phenotype in Nurr l-overexpressing neural stem cells by type 1 astrocytes. Nat Biotechnol 1999;17:653-9.

38 Stull ND, lacovitti L. Sonic hedgehog and FGF8: inadequate signals for the differentiation of a dopamine phenotype in mouse and human neurons in culture. Exp Neurol 2001;169:36-43

39 Armstrong RJ, Jain M, Barker RA. Stem cell transplantation as an approach to brain repair. Expert Opin Ther Patents $2001 ; 11: 1563-82$

40 Englund U, Bjorklund A, Wictorin K. Migration patterns and phenotypic differentiation of long-term expanded human neural progenitor cells after transplantation into the adult rat brain. Brain Res Dev Brain Res 2002;134: 123-41.

41 Rubio FJ, Bueno C, Villa A, et al. Genetically perpetuated human neural stem cells engraft and differentiate into the adult mammalian brain. Mol Cell Neurosci 2000;16:1-13. 
42 Svendsen CN, Caldwell MA. Neural stem cells in the developing central nervous system: implications for cell therapy through transplantation. Prog Brain Res 2000; 127: 13-34.

43 Caldwell MA, Svendsen CN. Heparin, but not other proteoglycans potentiates the mitogenic effects of FGF-2 on mesencephalic precursor cells. Exp Neurol 1998;152:1-10.

44 Studer L, Tabar V, McKay RD.

Transplantation of expanded mesencephalic precursors leads to recovery in parkinsonian rats. Nat Neurosci 1998;1:290-5.

45 Corti O, Sabate O, Horellou P, et al. A single adenovirus vector mediates

doxycycline-controlled expression of tyrosine hydroxylase in brain grafts of human neural progenitors. Nat Biotechnol 1999; 17:349-54.

46 Armstrong RJ, Watts C, Svendsen CN, et al. Survival, neuronal differentiation, and fiber outgrowth of propagated human neural precursor grafts in an animal model of Huntington's disease. Cell Transplant 2000;9:55-64.

47 Sinden JD, Rashid-Doubell F, Kershaw TR, et al. Recovery of spatial learning by grafts of a conditionally immortalized hippocampal neuroepithelial cell line into the ischaemia-lesioned hippocampus. Neuroscience 1997;81:599-608.

48 Hodges H, Sowinski P, Virley D, et al. Functional reconstruction of the hippocampus: fetal versus conditionally immortal neuroepithelial stem cell grafts. Novartis Found Symp 2000;231:53-65.

49 Saporta S, Borlongan CV, Sanberg PR. Neural transplantation of human neuroteratocarcinoma (hNT) neurons into ischemic rats. A quantitative dose-response analysis of cell survival and behavioral recovery. Neuroscience 1999;91:519-25.

50 Saporta S, Willing AE, Colina LO, et al. In vitro and in vivo characterization of $h N T$ neuron neurotransmitter phenotypes. Brain Res Bull 2000;53:263-8.

51 Kondziolka D, Wechsler L, Goldstein S, et al. Transplantation of cultured human neuronal cells for patients with stroke. Neurology 2000;55:565-9.

52 Nelson PT, Kondziolka D, Wechsler L, et al. Clonal human (hNT) neuron grafts for stroke therapy: neuropathology in a patient 27 months after implantation. Am J Patho 2002;160:1201-6.

53 Yandava BD, Billinghurst LL, Snyder EY "Global" cell replacement is feasible via

\section{What is wrong in conversion disorder? F Ovsiew}

\section{A disorder with many names}

T he article by Stone et al (this issue, $\mathrm{p}$ 591-596) $)^{1}$ addresses the natural history of a disorder with many names, none satisfactory. Functional, hysterical, psychogenic, medically unexplained, dissociative, conversion-all the names for this disorder have their faults. Yet the disorder is common, poses a management problem for doctors, and carries a poor prognosis. What is wrong with these patients?

What is now clearly known not to be wrong is the occult presence of a neurological disorder. Several follow up studies, this one included, show that the rate of erroneous diagnosis is low; neurological disease is not being missed when conversion disorder is diagnosed. Techniques of neurological examination that allow recognition of non-organic manifestations have been described, ${ }^{2}$ although patients with organic disease may-because of suggestibility and the "demand characteristics" of the setting, generate non-organic signs if called on to do so by inappropriate examination.

The follow up studies also show that most patients with conversion disorder have persisting, or remitting and relapsing, somatic symptoms. In addition, they have impairment of psychological and social functioning outside the sphere of medically unexplained somatic symptoms. For example, they often have mood disorders, self-injurious behaviour, dissociative symptoms, and interpersonal difficulties.
We have several clues about the fundamental nature of the disorder. Firstly, many of the patients have coexisting organic brain disease. Secondly, many have depressive disorders at the time of presentation with medically unexplained somatic symptoms. These facts point to the possibility of disruption of personality function by brain disease or by reversible abnormalities of brain state. Thirdly, however, many of the patients experienced sexual or physical abuse in childhood. This in itself, and as a proxy for widespread abnormality of the childhood environment, indicates that developmental factors are commonly implicated in the personality disturbance that gives rise (at times only intermittently) to conversion symptoms as well as (often persistently) to other failures of psychosocial functioning. ${ }^{4}$ As is always the case with personality disorder, heritable temperamental factors are likely to be relevant to vulnerability as well. ${ }^{5}$ In addition, patients often adduce the presence of contemporary "stress" in the origin of the symptoms. The evaluator strains to discover the actual direction of the causal arrow between personality dysfunction and chaotic or stressful life events. In Cloninger's words, "the development of a conversion or somatization disorder occurs as part of a complex adaptive process involving nonlinear interactions among multiple contributing factors". ${ }^{5}$ neural stem cell transplantation: evidence from the dysmyelinated shiverer mouse brain. Proc Natl Acad Sci USA 1999;96:7029-34.

54 Hammang JP, Archer DR, Duncan ID. Myelination following transplantation of EGF-responsive neural stem cells into a myelin-deficient environment. Exp Neurol 1997;147:84-95.

55 Snyder EY, Taylor RM, Wolfe JH. Neural progenitor cell engraftment corrects lysosomal storage throughout the MPS VII mouse brain. Nature 1995:374:367-70.

56 Arenas E. Stem cells in the treatment of Parkinson's disease. Brain Res Bull 2002;57:795-808

57 Aboody KS, Brown A, Rainov NG, et al. From the cover: neural stem cells display extensive tropism for pathology in adult brain evidence from intracranial gliomas. Proc Natt Acad Sci USA 2000:97:12846-51.

58 Benedetti S, Pirola B, Pollo B, et al. Gene therapy of experimental brain tumors using neural progenitor cells. Nat Med 2000;6:447-50

59 Herrlinger U, Woiciechowski C, Sena-Esteves $M$, et al. Neural precursor cells for delivery of replication-conditional HSV-1 vectors to intracerebral gliomas. Mol Ther 2000; 1:347-57

In summary, conversion disorder appears to be a disorder of affect regulation and symbolisation, in which somatic experiences and complaints serve torepresent and convey emotional distress, a purpose to which they are poorly suited. Ideally, the management of these patients centres on the formation of a treatment relationship not to catch the patient out but to allow exploration of areas of the patient's life outside the presenting symptoms and construction of a plan to reduce distress (including focused treatment of commonly coexisting depressive disorder), and to develop alternative ways of seeking attention and assistance for distress.

J Neurol Neurosurg Psychiatry 2003;74:557

\section{Author's affiliation}

F Ovsiew, Department of Psychiatry MC3077, University of Chicago, $5841 \mathrm{~S}$. Maryland Avenue, Chicago, IL 60637, USA;

f-ovsiew@uchicago.edu

\section{REFERENCES}

1 Stone J, Sharpe M, Rothwell P, et al. The 12 year prognosis of unilateral functional weakness and sensory disturbance. J Neurol Neurosurg Psychiatry 2003;74:591-6.

2 Stone J, Zeman A, Sharpe M. Functional weakness and sensory disturbance. J Neurol Neurosurg Psychiatry 2002:73:241-5.

3 Gould R, Miller BL, Goldberg MA, et al. The validity of hysterical signs and symptoms. J Nerv Ment Dis 1986;174:593-7.

4 Meares R, Stevenson J, Gordon E. A Jacksonian and biopsychosocial hypothesis concerning borderline and related phenomena. Aust N Z J Psychiatry 1999;33(6):831-40.

5 Cloninger CR. The origins of DSM and ICD criteria for conversion and somatization disorders. In: Halligan PW, Bass C, Marshall JC, eds. Contemporary approaches to the study of hysteria. Oxford: Oxford University Press, 2001:49-62. 